\title{
Kinetics of gene expression of alkaline phosphatase during healing of alveolar bone in rats
}

\author{
Willian Caetano Rodrigues ${ }^{\text {a,* }}$, André Luís da Silva Fabris ${ }^{a}$, Jaqueline Suemi Hassumi ${ }^{b}$, \\ Alaíde Gonçalves $^{\mathrm{b}}$, Celso Koogi Sonoda ${ }^{\mathrm{a}}$, Roberta Okamoto ${ }^{\mathrm{b}}$ \\ a Surgery \& Integrated Clinic Department, Araçatuba Dental School, São Paulo State University “Júlio de Mesquita Filho" (UNESP), Araçatuba, \\ São Paulo, Brazil \\ b Basic Sciences Department, Araçatuba Dental School, São Paulo State University “Júlio de Mesquita Filho” (UNESP), Araçatuba, São Paulo, Brazil \\ Accepted 14 February 2016 \\ Available online 28 February 2016
}

\begin{abstract}
Immunohistochemical studies and molecular biology have enabled us to identify numerous proteins that are involved in the metabolism of bone, and their encoding genes. Among these is alkaline phosphatase (ALP), an enzyme that is responsible for the initiation of mineralisation of the extracellular matrix during alveolar bone repair. To evaluate the gene expression of ALP during this process, we studied nine healthy adult male rats, which had their maxillary central incisors extracted from the right side and were randomly divided into three groups. During three experimental periods, 7 days, 14 days, and 28 days, the alveoli were curetted, the rats killed, and samples analysed by real-time reverse transcription polymerase chain reaction (qRT-PCR). The RNAm that encodes the gene for the synthesis of ALP was expressed during the three periods analysed, but its concentration was significantly increased at 14 and 28 days compared with at 7 days. There was no significant difference between 14 and 28 days $(\mathrm{p}=0.0005)$. We conclude that genes related to ALP are expressed throughout the healing process and more intensively during the later periods (14 and 28 days), which coincides with the increased formation of mineralised bone.
\end{abstract}

(C) 2016 The British Association of Oral and Maxillofacial Surgeons. Published by Elsevier Ltd. All rights reserved.

Keywords: alveolar bone repair; tooth socket; bone biology; mineralization; alkaline phosphatase; gene expression

\section{Introduction}

Scientific predictability of clinical treatments in oral and maxillofacial surgery, implantology, and periodontics is closely related to knowledge of the biopathology of bone. The morphophysiological characterisation and understanding of the dynamics of bony repair are fundamental to the

\footnotetext{
* Corresponding author at: Surgery \& Integrated Clinic Department, Araçatuba Dental School, São Paulo State University "Júlio de Mesquita Filho" (UNESP), Rua José Bonifácio, 1193, Vila Mendonça, Araçatuba, São Paulo (SP), Brazil, (CEP): 16015-050.

Tel.: +55 (18) 3636-3241/+55 (18) 98149-9430.

E-mail address: ortowill@yahoo.com.br (W.C. Rodrigues).
}

development of better treatments, including oral rehabilitation with bone grafts and implant-supported prostheses. ${ }^{1}$

Experimental studies involving immunohistochemical techniques and molecular biology have allowed identification of several proteins that are involved in the metabolism of bone, among which is alkaline phosphatase (ALP), a specific glycoprotein that is related to the early stages of differentiation of osteoblasts, and seems to be responsible for enabling the growth of hydroxyapatite crystals early in the formation of bone. ${ }^{2-4}$

The extraction of upper incisors in rats is a common experimental model for the evaluation of repair of alveolar bone, which can be divided into three phases with different histological features: exudative (marked by the fibrin synthesis), proliferative marked by formation of granulation tissue), and 
reparative (characterised by the synthesis of collagen, mineralisation, and remodelling). ${ }^{5-7}$ The socket is considered healed when it is totally filled by newly-formed bone and the alveolar crest has been remodelled, which happens after 28 days in rats $^{7}$ and 64 days in humans. ${ }^{5}$

During alveolar repair it is necessary to increase the neoformation of bone. A cascade of molecular signalling related to the local inflammatory process leads to recruitment, differentiation, and maturation of large numbers of osteoblasts. Osteogenesis is then initiated by stimulus of the transcription of specific mRNA molecules that, in turn, encode the translation of proteins related to bony metabolism. ${ }^{8} \mathrm{~A}$ better assessment of how the genes that encode ALP are expressed during the repair of alveolar bone in animals in homeostatic conditions will provide data that can contribute to future studies, not only to the optimisation of the process, but also for comprehension of healing disorders that arise from systemic changes that affect the skeleton.

The purpose of this study, therefore, was to investigate the dynamics of the expression of the ALP gene during healing of the alveolar bone in healthy rats by quantifying messenger RNA that encodes the specific gene for synthesis of this enzyme using the qRT-PCR technique (Real-time reverse transcription polymerase chain reaction).

\section{Animals and methods}

All ethical principles and national laws for the use of laboratory animals were followed, and the study was approved by the Ethics Committee on Animal Experimentation of the Araçatuba Dental School, São Paulo State University "Júlio de Mesquita Filho”, Brazil (approval number: 00123-2013).

\section{Animals}

Nine adult, male, Wistar rats (Rattus norvegicus albinus), body weight $250-300 \mathrm{~g}$, bred in the Animal Care Unit of the Araçatuba Dental School for purposes of education and research, were selected for the study and randomly distributed into three groups of three animals each: three were studied for 7 days, three for 14 days, and three for 28 days.

From the week before, and throughout the whole experimental period, the animals were kept in cages in a stable environment (temperature $22(2)^{\circ} \mathrm{C}$ ) with a 12 hour light/dark cycle. They were fed on solid crushed chow (Ração Ativada Produtor ${ }^{\circledR}$, Anderson \& Clayton S.A. - Laboratório Abbot Ltda., São Paulo, SP, Brazil) and had free access to water, except during the 12 hours preoperatively.

\section{Extraction of the upper right central incisor}

The operations were done aseptically, and all nine rats had their tooth extraction on the same day. They were weighed and then anaesthetised by intramuscular injection of xylazine hydrochloride (Coopazine ${ }^{\circledR}$ - Coopers Brazil Ltda, Cotia, SP, Brazil) $0.03 \mathrm{ml} / 100 \mathrm{~g}$ body weight followed by ketamine hydrochloride (Vetaset ${ }^{\circledR}$ - Fort Dodge Animal Health, Iowa, USA) $0.07 \mathrm{ml} / 100 \mathrm{~g}$ body weight.

The anterior portion of the maxilla was wiped with antiseptic (polyvinylpyrrolidone iodine, PVPI 10\% Topic Riodeine ${ }^{\circledR}$, Riodeine Chemical Industry, Ltda, São José do Rio Preto, SP, Brazil) before extraction of the upper right incisor with the aid of specially adapted instruments. ${ }^{5}$ The gingival fibromucous was then sutured with $4 / 0$ polyglactin 910 (Vicryl), and a dose of pentabiotic $(0.1 \mathrm{ml} / \mathrm{kg}$, Fort Dodge Animal Health Ltda, Campinas, São Paulo, Brazil) was given intramuscularly.

\section{Molecular analysis}

The samples of bone for analysis were collected at three different stages of repair of the alveolar bone so that we could evaluate the expression of the gene that encodes ALP synthesis. The transcriber mRNA was quantified using qRT-PCR.

Within 7,14 , and 28 days ( $n=3$ in each group) after the extraction of the right upper incisor, the rats had a further procedure that followed the same preoperative protocol as previously. Fragments of bony tissue were obtained from the middle third of each alveolus with a rongeur, thoroughly washed in phosphate buffered saline, and frozen at $75^{\circ} \mathrm{C}$ in liquid nitrogen, after which the rats were killed with an overdose of anaesthetic.

To achieve the highest purity and suitable concentration, total RNA was extracted by ultracentrifugation of the cell sample with Trizol reagent (Life Technologies Invitrogen, Carslbad, CA, USA). After RNA processing for the removal of introns (splicing), capping of the extremity $5^{\prime}$ and polyadenylation of the $3^{\prime}$ end, we obtained mRNA. Each complementary DNA sample (cDNA), which subsequently served as a template for amplification by PCR, was obtained from mRNA $1 \mu \mathrm{g}$ by enzymatic reverse transcription (MMLV reverse transcriptase - Promega Corporation, Madison, WI, USA).

The processing of qRT-PCR reactions involved the CFX96 thermocycler (Bio-Rad Laboratories, Philadelphia, PA, USA), the system SybrGreen PCR Master Mix (Applied Byosistems, Warrington, UK) and ALP specific primers (sense ribbon: ACGTGGCTAAGAATGTCATC and antisense ribbon: CTGGTAGGCGATGTCCTTA), designed using the Primer Express ${ }^{\circledR}$ software (Applied Biosystems, Foster City, CA). The standard PCR conditions adopted were $50^{\circ} \mathrm{C}$ ( 2 minutes), $95^{\circ} \mathrm{C}(10$ minutes $)$, and 40 cycles of $95^{\circ} \mathrm{C}$ ( 15 seconds), $60^{\circ} \mathrm{C}$ ( 1 minute), followed by a standard denaturation curve.

The relative gene expression was calculated in reference to the expression of mitochondrial ribosomal proteins and normalised by the gene expression of bone fragments removed 
from the alveoli during repair at the different experimental periods $-\Delta \Delta \mathrm{C}_{\mathrm{T}}$ method. ${ }^{9}$

The experiment was done in quadruplicate and the data compared by analysis of variance (ANOVA) and Tukey's post test with a probability of 0.0005 .

\section{Results}

Twelve measurements of relative gene expression of mitochondrial ribosomal ALP protein were obtained for each experimental period. The arithmetic mean (SD) of the four measures of each sample in the three groups is shown in Table 1. The mean of the values obtained for samples from rats 1-3 in the 7-day group was then calculated, and each sample in the 14 and 28 day groups was compared with the 7-day mean, which generated a relative quantification of expression of the ALP gene throughout the period of wound healing (Table 2).

mRNA that encodes the gene for ALP synthesis was expressed during the three periods, but its expression was significantly increased at 14 and 28 days of the wound healing process in compared with the 7-day mean $(\mathrm{p}=0.0005)$.

There was no significant difference between the ALP relative gene expression measured by qRT-PCR between periods of 14 and 28 days $(\mathrm{p}=0.0005)$.

Table 1

Relative quantification of the transcriber mRNA for each specimen in three different experimental periods. The values were normalised by the $\Delta \Delta \mathrm{C}_{\mathrm{T}}$ method. ${ }^{9}$

\begin{tabular}{llll}
\hline & At 7 days & At 14 days & At 28 days \\
\hline Rat 1 & 0.849 & 1.510 & 2.265 \\
& 1.027 & 1.902 & 2.190 \\
& 1.086 & 1.524 & 2.421 \\
Mean (SD) & 1.615 & 1.723 & 2.012 \\
Rat 2 & $1.144(0.329)$ & $1.665(0.186)$ & $2.222(0.17)$ \\
& 0.778 & 1.934 & 1.795 \\
& 0.904 & 1.954 & 1.769 \\
Mean (SD) & 0.797 & 2.025 & 1.744 \\
Rat 3 & 0.807 & 1.954 & 1.762 \\
& 1.183 & $1.967(0.04)$ & $1.767(0.021)$ \\
& 1.024 & 1.032 & 1.322 \\
Mean (SD) & 1.162 & 1.095 & 1.304 \\
\hline
\end{tabular}

Table 2

Relative expression of the gene that encodes the alkaline phosphatase synthesis in the three experimental periods. Comparison between the mean (SD) samples of the 14 and 28 day periods and the mean (SD) of the seven-day samples: $1.022(0.15)$.

\begin{tabular}{lll}
\hline Rats & 14 days & 28 days \\
\hline 1 & $1.665(0.186)$ & $2.222(0.17)$ \\
2 & $1.967(0.04)$ & $1.767(0.021)$ \\
3 & $1.066(0.052)$ & $1.364(0.143)$ \\
\hline
\end{tabular}

\section{Discussion}

The clinical and scientific relevance of deciphering the biochemical signalling pathways, and the action mechanisms of each protein synthesised by the cells involved in the repair of the dental socket, is a better understanding of how the body produces high quality bone so quickly. The evaluation of how the encoding genes of the synthesis of these proteins are expressed can also contribute to the optimisation of the formation and remodelling of bone tissue in homeostatic conditions, as in systemic changes that affect the skeleton.

There are numerous proteins that are considered markers of bony formation: collagen I, osteocalcin, osteonectin, osteopontin, and bone sialoprotein. ${ }^{2,10-12}$ Particular emphasis has been put on ALP, which is considered the earliest manifestation of the osteoblastic phenotype when the process of differentiation of osteoprogenitor cells is stimulated. ${ }^{13}$ It is an enzyme encoded by the non-specific tissue gene A1P, located on chromosome $\mathrm{A}$, which is presented in various molecular forms in the circulation, all obedient to the same peptide structure of 507 amino acids. ${ }^{2,3}$

When hydroxyapatite crystallites come into contact with the interstitial fluid, pyrophosphate ions are deposited on their surfaces to inhibit the continuity of the growth. Under alkaline conditions, the role of ALP is to hydrolyse these ions from an organic radical and favour the structuring of the hydroxyapatite crystallites. ${ }^{14,15} \mathrm{~A}$ minimum amount of ALP activity has to be reached for apatite nucleation to start, and a moderate reduction in gene expression and ALP enzyme activity would be enough to impair the mineralisation process. ${ }^{16}$

The immunohistochemical method evaluates only the in situ expression of the already synthesised (translated) protein in the ribosomes, and is a more subjective assessment and dependent on the evaluator. ${ }^{17,18}$ The quantification of the mRNA expression that encodes the gene responsible for the synthesis of the enzyme would be more objective. However, when it comes to the assessment of enzyme activity, these molecular data should be interpreted with caution. ${ }^{19}$ Numerous authors $4,16,20,21$ have assumed that there is a 1:1 ratio between the measured mRNA and the expression of the associated protein, but relatively recent studies have shown that this relation between transcription and translation is almost always invalid, and follows complex mathematical modelling. ${ }^{17,19}$

Considering the high specificity and sensitivity of qRTPCR and its limited use in studies specifically related to alveolar bone repair, we developed the present study to assess expression of the ALP gene during the process. The results showed that the expression of mRNA for ALP protein synthesis occurs throughout the whole process of wound healing, and not only in the initial stages. There was a significant increase in gene expression at 14 days compared with seven days. Although gene expression at 28 days was 
slightly higher than at 14 days, there was no significant difference between the two periods. These data do not support those of previous studies, the results of which showed a significant decrease in ALP gene expression during the later stages. $^{4,21}$

There is strong evidence that the ALP enzyme manifests itself more intensively during the early stages of formation of bony tissue, with a significant decrease during the final phases of repair. ${ }^{13,22,23}$ A Chinese group found dissociation between the peak of ALP activity and the point of maximum mRNA expression of the ALP enzyme. ${ }^{24}$ How can we explain that? Why is there no synthesis of ALP protein in the same proportion of the related gene transcription rates during the whole process?

We can suppose that in later periods of bony repair the mRNA expression related to ALP stays high, but somehow, in a way that we do not yet understand, the gene may start contributing to the activation of some other pathway of enzyme production, and reduce the stimulus for the translation of the ALP protein.

Osteocalcin (GLA - protein) is associated with calcium binding to the extracellular collagen matrix, and can be used as a biochemical marker of formation of bone. ${ }^{25} \mathrm{In}$ a previous study we concluded that expression of osteocalcin is more pronounced at 14 and 21 days postoperatively, which characterises the periods when there is intense mineralisation of bone during healing of alveolar bone. ${ }^{12} \mathrm{We}$ hypothesised that there is some interrelation between the biochemical signalling pathways for ALP and osteocalcin synthesis in the intermediary and final stages of alveolar repair.

These data about greater expression of the ALP gene in later periods may be a major contribution to understanding the complex dynamics of alveolar bone repair after tooth extraction, and may support future studies of other related proteins and animals with systemic disorders.

We conclude that even within the limitations of the present study the genes related to the synthesis of ALP are expressed during the whole process of repair and more in the later periods, which coincides with the increase in formation of mineralised bone.

\section{Conflict of Interest}

We have no conflicts of interest.

\section{Ethics statement/confirmation of patients' permission}

All ethical principles and national laws of laboratory animals use were followed and the study was approved by the Ethics Committee on Animal Experimentation of the Araçatuba Dental School, São Paulo State University “Júlio de Mesquita Filho”, Brazil (approval number: 00123-2013).

\section{Acknowledgement}

The authors wish to express their gratitude to Fabiola Singaretti de Oliveira, from Ribeirão Preto Dental School, São Paulo University (FORP-USP) by the aid in the reactions of molecular analysis (qRT-PCR).

\section{References}

1. Barone A, Todisco M, Ludovichetti M, et al. A prospective, randomized, controlled, multicenter evaluation of extraction socket preservation comparing two bovine xenografts: clinical and histologic outcomes. Int J Periodontics Restorative Dent 2013;33:795-802.

2. Vieira JG. Considerations about biochemical bone metabolism markers and their practical usefulness (in Portuguese). Arquivos Brasileiros Endocrinologia Metabologia 1999;43:415-22.

3. Hoylaerts MF, Ding L, Narisawa S, et al. Mammalian alkaline phosphatase catalysis requires active site structure stabilization via the N-terminal amino acid microenvironment. Biochemistry 2006;45: 9756-66.

4. Poleti ML. Morphometric, molecular and radiographic analysis of the alveolar repair process after antimicrobial photodynamic therapy in Wistar rats (in Portuguese). (Dissertation for Master's degree) Bauru (SP): São Paulo University, School of Dentistry, 2009.

5. Amler MH. The time sequence of tissue regeneration in human extraction wounds. Oral Surg Oral Med Oral Pathol 1969;27: 309-18.

6. Okamoto T, de Russo MC. Wound healing following tooth extraction. Histochemical study in rats. Rev Fac Odontol Araçatuba 1973;2: 153-69.

7. Carvalho TL, Bombonato KF, Brentegani LG. Histometric analysis of rat alveolar wound healing. Braz Dent J 1997;8:9-12.

8. Eriksen EF. Cellular mechanisms of bone remodeling. Rev Endocr Metab Disord 2010;11:219-27.

9. Livak KJ, Schmittgen TD. Analysis of relative gene expression data using real-time quantitative PCR and the $2^{-\Delta \Delta C T}$ method. Methods 2001;25:402-8.

10. Katagiri T, Takahashi N. Regulatory mechanisms of osteoblast and osteoclast differentiation. Oral Dis 2002;8:147-59.

11. Karsenty G. Bone formation and factors affecting this process. Matrix Biol 2000;19:85-9.

12. Rodrigues Luvizuto E, Monica Dias S, Chiantelli Cláudio-Coutinho $\mathrm{C}$, et al. Temporal localization of osteocalcin protein during healing of tooth extraction sockets in rats. Minerva Stomatol 2010;59: 355-61.

13. Miranda SC, Silva GA, Hell RC, et al. Three-dimensional culture of rat BMMSCS in a porous chitosan-gelatin scaffold: A promising association for bone tissue engineering in oral reconstruction. Arch Oral Biol 2011;56:1-15.

14. Addison WN, Azari F, Sorensen ES, et al. Pyrophosphate inhibits mineralization of osteoblast cultures by binding to mineral, up-regulating osteopontin, and inhibiting alkaline phosphatase activity. J Biol Chem 2007;282:15872-83.

15. Bonucci E. Understanding nanocalcification: a role suggested for crystal ghosts. Mar Drugs 2014;12:4231-46.

16. Wennberg C, Hessle L, Lundberg P, et al. Functional characterization of osteoblasts and osteoclasts from alkaline phosphatase knockout mice. $J$ Bone Miner Res 2000;15:1879-88.

17. Lee PS, Shaw LB, Choe LH, et al. Insights into the relation between mRNA and protein expression patterns: II. Experimental observations in Escherichia coli. Biotechnol Bioeng 2003;84:834-41.

18. Luvizuto ER, Dias SS, Okamoto T, et al. Raloxifene therapy inhibits osteoclastogenesis during the alveolar healing process in rats. Arch Oral Biol 2011;56:984-90. 
19. Mehra A, Lee KH, Hatzimanikatis V. Insights into the relation between RNAm and protein expression patterns: I. Theoretical considerations. Biotechnol Bioeng 2003;84:822-33.

20. Zernik J, Twarog K, Upholt WB. Regulation of alkaline phosphatase and alpha 2 (I) procollagen synthesis during early intramembranous bone formation in the rat mandible. Differentiation 1990;44:207-15.

21. Cardoso CL, Ferreira Júnior O, Carvalho PS, et al. Experimental dry socket: microscopic and molecular evaluation of two treatment modalities. Acta Cir Bras 2011;26:365-72.

22. Bronckers AL, Gay S, Finkelman RD, et al. Developmental appearance of Gla proteins (osteocalcin) and alkaline phosphatase in tooth germs and bones of the rat. Bone Miner 1987;2:361-73.
23. Effah Kaufmann EA, Ducheyne P, Shapiro IM. Evaluation of osteoblast response to porous bioactive glass (45S5) substrates by RT-PCR analysis. Tissue Eng 2000;6:19-28.

24. Li R, Li X, Zhou M, et al. Quantitative determination of matrix Gla protein (MGP) and BMP-2 during the osteogenic differentiation of human periodontal ligament cells. Arch Oral Biol 2012;57: 1408-17.

25. Han XL, Meng Y, Kang N, et al. Expression of osteocalcin during surgically assisted rapid orthodontic tooth movement in beagle dogs. J Oral Maxillofac Surg 2008;66:2467-75. 